\title{
The acquisition of ergative languages ${ }^{1}$
}

\author{
CLIFTON PYE
}

Abstract

Ergative languages have challenged the ingenuity of linguists for more than a century. This article explores learnability problems associated with the acquisition of ergative languages. Traditionally, an ergative language is one which treats the subjects of intransitive verbs in the same way as the objects of transitive verbs. Languages may have rules which operate on a morphologically or syntactically ergative basis, but all languages are syntactically accusative to some extent. Both types of ergativity raise problems for language-acquisition theory. Children acquiring ergative morphologies must learn to distinguish between the subjects of transitive and intransitive verbs. Acquisition data suggest that children acquire ergative and accusative morphological systems equally easily. This finding supports a distributional learning procedure. Learnability considerations rule out the existence of syntactically ergative languages in the sense of Marantz's (1984) ergativity hypothesis. Unambiguous evidence of syntactic ergativity only appears in complex sentences; thus, children cannot use data within simple, active sentences to establish whether or not their language is syntactically ergative. Children acquiring languages with ergative syntactic constructions must learn when the direct object of a transitive verb functions as a syntactic pivot. Acquisition data for ergative syntactic constructions in K'iche' and Kaluli suggest that children initially fail to recognize ergative constraints on syntactic rules. This finding supports semantic bootstrapping as an acquisition mechanism for the initial construction of syntactic structure.

\section{Introduction}

Ergative languages have challenged the ingenuity of linguists for more than a century (Dixon 1979; Plank 1979). In this paper I will explore the 
learnability problems associated with ergative languages and how current theories of language acquisition may or may not be able to solve them. Many explanations of language acquisition assume that children depend on the semantic relation agent to establish the initial grammatical relation of subject. Ergative languages, however, distinguish between the subjects of transitive and intransitive verbs at some level of morphosyntactic structure. This distinction provides an ideal test of the relative importance of semantic versus distributional analyses in children's initial grammatical development.

Ergative languages exhibit a different pattern of morphosyntactic relations than the more common accusative languages. Accusative languages (such as English, French, Russian) treat the agents of transitive and intransitive verbs alike. An ergative language is one in which the subject of an intransitive verb is treated in the same way as the object of a transitive verb. In morphologically ergative languages the subject of an intransitive verb has the same morphological marking as the object of a transitive verb. Some linguists claim that languages may be syntactically as well as morphologically ergative. In syntactically ergative languages the theme or patient of transitive verbs rather than the agent bears the grammatical relation of subject. Agents are realized as grammatical objects (Dixon 1979 provides a thorough overview of the many different types of ergative constructions; see also Anderson 1976; Mallinson and Blake 1981; Silverstein 1976; and the articles in Plank 1979).

It is impossible to discuss ergative syntactic constructions without some means of distinguishing between syntactic and semantic relations. Most of the terminology for these relations in the linguistics literature assumes an accusative structure. I will use the terms subject and object in a strictly syntactic sense to refer to grammatical relations that are defined solely in terms of syntactic criteria. I will use Dixon's (1979) terminology in order to specify particular semantic relations. Dixon uses $[A]$ to refer to the participant in multiparticipant events who potentially initiates or controls the activity (1979: 104). The other participant in events denoted by transitive verbs is the [O]. Dixon uses [S] to refer to the sole participant involved in activities expressed by intransitive verbs.

I am quite aware that I am using Dixon's terminology to differentiate between basic semantic relations despite the absence of any theoretical grounding for it. Although I am not the only linguist who distinguishes semantic relations in this way (see Chomsky 1981; Fillmore 1968; Levin 1983; Marantz 1984; Perlmutter and Postal 1977), this is small comfort (see DeLancey 1984; Dowty 1988). Even though there is no theoretical account of semantic relations, there is strong empirical evidence for the 
operation of some basic set of semantic relations. For example, Dixon observes that 'the A NPs for "cut', "give", "see" etc. are consistently treated in exactly the same way, in all aspects of morphology and syntax, across every type of human language' (1979: 103). The existence of grammatical rules such as the passive which change the relation between the semantic role of $A$ and the grammatical subject shows that it is not logically necessary for languages to treat As in a consistent syntactic fashion. The uniform treatment of As across verb types and across languages strongly suggests that a uniform semantic relation is involved in the construction of most sentences with transitive verbs.

This treatment still leaves many verbs for which there is no obvious $A$ NP which initiates or controls the activity. The $A$ relation may be extended to one of the participants through some culturally perceived similarity of the event to an activity that is controllable. Dixon mentions the verbs like, annoy, endure, attract, and undergo in this context. The small number of such verbs in comparison to the controllable-action verbs underlines the pervasiveness of the $A$ relation. There is also reason to believe that the $\mathrm{S}$ role is not a simple, uniform semantic role for all intransitive verbs (see Rosen 1984). The existence of distinct morphosyntactic treatments for the subjects of intransitive verbs leads Dixon to distinguish 'split-S' and 'fluid-S' languages from languages in which the $S$ receives a uniform grammatical treatment.

The next section discusses the learnability of morphologically ergative languages. Section 3 discusses the learnability of syntactically ergative languages. The sections first define the relevant notions of morphological and syntactic ergativity before proceeding to a discussion of the learnability problems, acquisition hypotheses, and acquisition data currently available for each class of ergative language. I present my own solutions to the learnability problems raised by ergative languages in section 4 . I conclude that it is possible to explain the acquisition of morphologically ergative languages, but not syntactically ergative languages. This leads to the rather drastic solution of assuming that syntactically ergative languages, in the sense specified by Marantz's (1984) ergativity hypothesis, do not exist.

\section{Morphological engativity}

An example of morphological ergativity is shown in (I), which contrasts the ergative cross-neferencing system of the Mayan language $\mathrm{K}^{\prime}$ iche'2 with the accusative pronominal system of English. 
(1)

\begin{tabular}{|c|c|c|c|}
\hline Accusative & & Ergative & \\
\hline English & He comes & K'iche' & $\begin{array}{l}\text { k-0-pe:t-ik } \\
\text { INCOMP-3A-come-TIV }\end{array}$ \\
\hline & He sees me & & $\begin{array}{l}\text { k-in-r-il-oh } \\
\text { INCOMP-1A-3E-see-TTV }\end{array}$ \\
\hline & I see him & & $\begin{array}{l}\text { k-0-inw-il-oh } \\
\text { INCOMP-3A-1E-see-TTV }\end{array}$ \\
\hline
\end{tabular}

In accusative languages, the subjects of transitive and intransitive verbs are alike in that they both take a nominative marker (either a case marker on the noun or a cross-reference marker on the verb), while the object of transitive verbs is distinguished by receiving an accusative marker. Ergative languages, in contrast, treat the subject of intransitive verbs and the object of transitive verbs alike in that they both have an absolutive marker, while the subject of transitive verbs is distinguished with an ergative marker. Note that the third-person subject of the K'iche' transitive verb in (1) has the ergative cross-reference marker $r$-, while the thirdperson subject of the $K$ 'iche' intransitive verb has a zero morpheme that is the absolutive cross-reference marker. The English pronouns demonstrate the case marking of a morphologically accusative language. The English system of subject-verb agreement also follows an accusative pattern.

Case marking and cross-referencing systems are examples of what Nichols (1986) refers to as dependent marking and head marking, respectively. The verb usually serves as the head of its clause, while the nounphrase arguments of the verb are its dependents. In addition to these two major patterns, Nichols notes two further types: (1) the complete absence of formal marking (as in Chinese), and (2) double marking, where both head and dependents have formal markers (as in Polish).

Languages also show various degrees of consistency in their casemarking and cross-referencing systems. The K'iche' system of person marking is unusual in that it is ergative throughout the different persons, aspects, and clause levels. The morphology of most ergative languages is only partially ergative, with an accusative morphology entering at some point in the system. These are referred to as 'split-ergative' languages. In the other Mayan languages, ergative morphology may be limited to the main clause (Jacaltec), past tense (Mopan), a certain degree of humanness or animacy (Mocho), or unfocused constituents (Ixil) (see Larsen and Norman 1979). Split-ergative morphological systems are also common in the Australian Aboriginal languages. Dyirbal, for example, uses an accusative case-marking system for the first- and second-person pronouns and an ergative system for third-person pronouns (Dixon 1979). 
Double-marking languages may also exhibit mixed morphological systems. The Australian Aboriginal language Walbiri uses an ergative casemarking system on NPs and an accusative cross-referencing system on verbs (Van Valin 1981; see also Mallinson and Blake 1981: 59-65). Finally, there are languages, such as the Ngura group of Australian languages, which use distinctive markers for all three semantic relations A, S, and $O$ (Dixon 1979). Mallinson and Blake cite Wangkumara as an example of this type (1981: 50).

\subsection{The learnability of morphologically ergative languages}

Simple, morphologically ergative languages create difficulties for most acquisition theories. Any theory which failed to distinguish between the $A$ and $S$ semantic relations would predict that children initially treat $A$ and $S N_{3}$ in the same fashion (for example, Bates and MacWhinney 1982; Brown 1973; Bruner 1975; Pinker 1984). If children use cognitive strategies which assume that single morphemes mark single functions, they should be even more determined to use one marker for the $A$ and $S$ NPs to the extent that these NPs bear the same function (KarmiloffSmith 1979: Slobin 1985). An alternative functionalist strategy that children might use would be to seek distinct morphological treatments for $A, S$, and O NPs. In this section I will discuss the predictions several theoretical accounts of morphological acquisition make for the development of ergative morphological systems.

Slobin (1985: 1174) proposes that children initially map 'functors' (inflections, etc.) onto a universal set of basic, language-neutral notions rather than onto the language-specific categories of meaning in the adult language. His discussion of the acquisition of accusative and ergative inflections assumes that both are initially unanalyzed units associated with the manipulative activity soene (1985: 1177). Slobin states that eventually, casemarking will be extended to relatively desemanticized grammatical roles ... by means of partial similarity, metaphoric extension, and the like' (1985: 1177-1778). His account is vague in two important respects. First, he only discusses case marking in relation to transitive verbs. ignoring the question of when children begin case-marking the subjects of intransitive verbs. Second, he assumes that partial similarity, etc., will be sufficient for children to extend their case-marking inflections accurately. begging the question of whether children use syntactic or semantic similarities to extend a nominative or absolutive case marking to the $\mathrm{Ss}$ of intransitive verbs or the As of less prototypical transitive verbs. 
In an effort to test Slobin's proposals, Bowerman (1985) outlines two strategies that children could in principle use to acquire morphologically ergative languages in a 'language-neutral' fashion. According to her first strategy, children would initially distinguish between the subjects and objects of transitive verbs (by means of case endings, word-order patterns, verb agreement, etc.) and leave the subjects of intransitive verbs unmarked. Eventually they would extend the absolutive marking to the subjects of intransitive verbs (children learning accusative languages would correspondingly extend the nominative). This would seem to be the process that Slobin had in mind. According to the second strategy, children would start by marking only the subjects of intransitive verbs and later extend this marker to the objects of transitive verbs. Bowerman finds no evidence that children use either strategy - a significant contradiction to Slobin's hypothesis. The children's use of case marking, word order, etc., seems to reflect the morphological pattern of the adult language from the beginning.

Pinker (1984) addresses the acquisition of morphological ergativity in several sections of his book. He employs the mechanism of semantic bootstrapping (Grimshaw 1981) to explain how children establish their initial set of syntactic rules. The semantic-bootstrapping hypothesis assumes that there is a universal correspondence between semantic roles and syntactic relations for a core set of relations. A semantic-bootstrapping mechanism that operates in terms of a simple agent relation would predict that children treat $A$ and S NPs in the same fashion. In his table of semantic-syntactic correspondences (Pinker 1984: 41) distinguishes between the agent of a transitive action and the actor of an intransitive action for the purpose of case marking. However, he combines these categories as the initial semantic basis for the subject relation. He leaves the inherent contradiction between these two (presumably innate) semantic categorizations unresolved. There is no mechanism in Pinker's system to prevent a child from distinguishing between $A$ and S NPs for the purpose of constructing an initial set of phrase-structure rules.

Pinker $(1984 ; 372$, note 15$)$ sketches two additional acquisition strategies which do not depend on semantic bootstrapping. His second strategy is similar to Bowerman's first: the child initially distinguishes between the case marking for the subject and object of transitive verbs and then extends the appropriate case marker to the subject of intransitive verbs. Pinker's first strategy is simply 'noticing whether the case marker for the intransitive actor is identical to the marker for the transitive agent ... or to the marker for the transitive patient ... . Such a strategy vitiates the need for built-in constraints in Pinker's acquisition theory, since children could theoretically use the same technique to notice gender marking and 
declensional systems, not to mention the constraints on phrase structure and transformations that Pinker uses as support for his theory.

In another section of his book (1984: 188-192). Pinker uses the acquisition of case distinctions to illustrate his model of inflectional acquisition. He hypothesizes that children first learn inflections on a word-by-word basis. Children would then form word-specific paradigms containing both ergative and absolutive inflections (or nominative and accusative inflections). After the children had acquired a sufficient number of individual lexical items they would be in a position to notice whether the subject or object of transitive verbs was marked in the same fashion as the subject of intransitive verbs. At this point they could construct a rule that would capture the language's morphological system, be it ergative or aocusative.

Such a mechanism, however, predicts that children would initially use case-marked nouns in a random fashion until they come up with the appropriate analysis for the case markers. For example, until children acquiring Latin discovered the word-specific paradigm femina (NOM) feminam (ACC), they might well use the nominative form femina as both a subject and a direct object. Anticipating the results of my survey of the acquisition data, I find no evidence for such a phase of random case marking. If children do use case markers initially without knowledge of their function, they manage to do so while respecting the grammatical constraints on the case-marked nouns.

This observation suggests that children rely instead upon some system of syntactic and semantic correlations such as that proposed by Maratsos and Chalkley (1980). Some type of distributional learning is the only way that children can discover an appropriate set of gender and declensional classes in their language (see Braine 1987). I suggest that children are also sensitive to the particular semantic roles associated with crossreference and case markers in languages which have these. Such a mechanism predicts that children will use case markers and cross-reference markers accurately from the time these markers first appear in their speech.

This model predicts that children mark the subjects of transitive and intransitive verbs appropriately at the same point in development, and further that they would acquire ergative and accusative morphological systems equally easily. In fact, distributional learning may even be extended to account for the acquisition of languages with a split-ergative morphology or a double marking system, as long as the children's input included examples of the difierent subject-marking systems.

There is another feature of Maratsos and Chalkley's model that warrants further consideration. Beyond an initial stage of correlation building. they propose a mechanism of generalization extraction. They use this 
procedure to explain the sequence of past-tense forms children produce when acquiring irregular verbs in English. After an initial period of errorless past-tense marking, children extend the regular past-tense ending to verbs with an irregular past-tense form (see Kuczaj 1977). Children use both the correct and the overgeneralized past-tense forms for a significant length of time before settling on the correct adult forms.

Case marking and cross-referencing systems raise a significant issue for this procedure - exactly what degree of regularity is required for the generalization procedure to operate? It is possible to analyze the regularity associated with case and cross-referencing morphology into at least three different components: (1) the degree to which the morphology is consistently ergative or accusative, (2) the degree to which adults use the morphology, and (3) the degree to which the morphology marks a productive lexical class in the language.

As I mentioned above, languages do not usually contain an ergative morphology that is consistent. The morphological splits occur in welldefined patterns, however, that remain consistent enough to pose little additional difficulty to the generalization procedure. For example, there is morphological splitting by tense/aspect, person, or clause type (Silverstein 1976). However, the other two components may be expected to affect the generalization procedure adversely. Japanese is a well-known example of a case-marking language in which adults usually omit the case markers when speaking to children (Clancy 1985). Although Japanese has an accusative pattern of case marking that is fairly consistent, children do not hear very many instances of the case markers in caretaker speech. I assume that children find it easier to learn a morphology that is always used rather than one with syntactic and pragmatic rules of ellipsis (see Ochs 1982).

A third component that might affect the generalization process is the degree to which the case-marking or cross-referencing features are attached to a productive lexical class in the language. German, for example, shows case distinctions on both determiners and adjectives. The case distinctions in English are limited to the set of independent pronouns. The generalization procedure of Maratsos and Chalkley works best when there are many members of a lexical class which exhibit a particular inflection. Otherwise, the procedure simply tracks the inflected words as separate lexical units. I propose treating morphological distinctions on open-class items separately from the distinctions on closed-class items. Maratsos and Chalkley's model would predict more accurate use of morphological distinctions on open-class items (for example, cross-referencing systems on verbs, case markers on nouns and adjectives) and less accurate use of morphological distinctions on closed-class items (for 
example, cross-referencing systems confined to auxiliary verbs, and case markers on pronouns or determiners).

A final consideration is the type of generalization that children will extract from input data. It is best to remember that even in the case of the acquisition of the English past-tense forms, overgeneralizations never amount to more than $10 \%$ of a child's use of irregular forms (see Cazden 1968; Ingram 1989; Ullman et al. 1989). Most of the time children are able to supply the correct form of an irregular morpheme. This fact suggests that such generalizations only serve as a last resort that is used when children (and adults) are unable to access a specific lexical entry (see Hoek et al. 1986).

It seems reasonable to distinguish between competence and performance overgeneralizations. A competence overgeneralization would reflect the addition of a new rule to the child's grammar, whereas a performance overgeneralization will reflect a default procedure that a child accesses when all else fails. I assume this distinction will be evident in the frequency of children's overgeneralizations. Children should make competence overgeneralizations close to $90 \%$ of the time they use any irregular morpheme, while making performance overgeneralizations less than $10 \%$ of the time.

Both types of overgeneralization provide evidence that children have extracted some generalization from the input. For example, performance overgeneralizations demonstrate that children recognize a similarity of function for distinct forms - for example, that there are distinct pasttense morphemes which serve the same function, or distinct case forms for NPs which are direct arguments of the verb (that is, subject and object). Such errors would be distinct from errors caused by random accessing of incorrect lexical forms, since random accessing should result in the occasional use of genitive or dative forms as well (that is, forms which do not appear in a direct argument relation to the verb). Only competence overgeneralizations prove that children have added an overly general rule to their grammar.

Maratsos and Chalkley's theory does not predict that children would overgeneralize in any particular direction. Children learning a language with an accusative morphology might produce ergative constructions, while children learning a language with an ergative morphology might produce accusative constructions. A distributional model of inflectional acquisition also predicts that children would be free to overgeneralize from transitive to intransitive sentences or vice versa. There are at least six possible types of extension: ${ }^{3}$

1. from intransitive subject to transitive subject;

2. from intransitive subject to transitive object; 
3. from transitive subject to intransitive subject;

4. from transitive object to intransitive subject;

5. from transitive subject to transitive object;

6. from transitive object to transitive subject.

In Table $1 \mathrm{I}$ list the effects such extensions would have on languages with either an accusative or an ergative morphology. In some cases the extension would neutralize the morphological distinction between subject and object. This process would result in a nonhuman type of language if the children neutralize the $\mathrm{A} / \mathrm{O}$ distinction but maintain a distinctive morphology for the $\mathrm{S}$. For example, children acquiring an accusative language could extend the accusative marker from Os to As but not to Ss. In other cases the extension would result in a morphological system that was the opposite of the adult language. In the next section, I will discuss which patterns are actually found in acquisition data.

All of these overgeneralizations are potentially correctable, since positive evidence is available from adult speakers. That is, a child who used an incorrect subject marker would hear other speakers using the correct form, just as children who overgeneralize the regular form of the past tense to irregular verbs in English hear other speakers using the irregular form. Thus, overgeneralization of either an ergative or an accusative morphology would be relatively harmless.

\subsection{Acquisition data}

Given the importance of case marking and cross-referencing morphologies for evaluating acquisition theories, it is appropriate to examine data that are currently available on the acquisition of both ergative and accusative morphological systems. In a paper of this length, I can only provide capsule summaries of the acquisition data. I cannot discuss all

Table 1. The effects of morphological extensions in morphologically ergative and accusative languages

\begin{tabular}{lll}
\hline Extension & $\begin{array}{l}\text { Initial morphology } \\
\text { accusative }\end{array}$ & ergative \\
\hline $1 . \mathrm{S} \rightarrow \mathrm{A}$ & correct & A,S,O neutralized \\
$2 . \mathrm{S} \rightarrow \mathrm{O}$ & A,S,O neutralized & correct \\
$\mathrm{A} \rightarrow \mathrm{S}$ & correct & accusative \\
$4 . \mathrm{O} \rightarrow \mathrm{S}$ & ergative & correct \\
$5 . \mathrm{A} \rightarrow \mathrm{O}$ & A,S,O neutralized & A,O neutralized \\
$6 . \mathrm{O} \rightarrow \mathrm{A}$ & A,O neutralized & A,S,O neutralized \\
\hline
\end{tabular}


of the intricacies involved in this data and I urge readers to consult the primary sources for details. I will discuss the acquisition data available for ergative languages in more detail since it is less familiar to many researchers.

2.2.1. English. A number of investigators have noted that children learning English may have some difficulty acquiring the case distinctions in the pronoun system (see Bellugi 1968; Budwig 1985; Huxley 1970; Tanz 1974). Huxley is the only investigator who provides the full set of data for her subjects. One child had little trouble learning to use the pronouns correctly, while a second child showed a prolonged usage of object pronouns for the subjects of both transitive and intransitive verbs. Budwig notes a tendency to use possessive pronouns as As, but this is not evident in Huxley's data. Thus, there appears to be a good deal of individual variation in acquiring English pronouns. Some children experience little difficulty with the case distinctions in the pronouns, while other children regularly extend the $\mathrm{O}$ pronouns to both $\mathrm{A}$ and $\mathrm{S}$.

2.2.2. Japanese. Acquisition data from Japanese suggests that children experience different degrees of difficulty learning to use the accusative system of case markers on Japanese NPs (Clancy 1985; Morokawa 1989; Yokoyama and Schaefer 1986). Japanese children first use case markers around 2;0, and the first case marker to appear is the subject marker $g a$. The most frequent error is the use of the subject marker $g a$ with the objects of transitive verbs. Clancy (1985: 389) states that this error is quite common. However, Morokawa reports that her subject only made such errors in .001 of his uses of $g a$. Both Clancy and Morokawa note that the case markers are usually omitted in adult speech to children. The object marker $o$ is omitted more frequently than the subject marker.

2.2.3. German. Mills (1985) gives a brief summary of children's acquisition of case distinctions in German. German marks accusativecase distinctions on articles, adjectives, and pronouns. The case distinctions on articles and adjectives are crosscut by gender distinctions, which actually simplify the case system by neutralizing the nominative/accusative distinction in the feminine and neuter genders. Thus, German children only need to make an overt case distinction on articles and adjectives that modify masculine nouns. Mills reports that the children learn to make this distinction by $2 ; 2$ with adjectives but are still making case errors with articles as late as 5;6. Mills states that German children overgeneralize the nominative form of the articles to Os. Mills claims that German children use case accurately with pronouns, but that it is 
difficult to determine how productive their knowledge is because they frequently use names in place of pronouns.

2.2.4. Polish. Smoczyńska (1985) reports that Polish children quickly acquire the accusative case distinctions on Polish nouns. They may use these markers by $1 ; 7$ and quickly develop different markers for the nominative, accusative, and genitive cases. She does not report whether the children make any cases errors but does note that the Polish data appear to be quite different from acquisition data on Russian. She suggests that one reason for this difference may be that the Polish data come from a large number of subjects, while the Russian data are based on the observation of a single child. Weist and Witkowska-Stadnik (1986) supply data from four children on the acquisition of the Polish case system that support and expand Smoczynska's observations. They also report data on the children's acquisition of the accusative cross-referencing system on Polish verbs. Their data indicate that the children were using this agreement system by $1 ; 8$. They do not state whether the children made any case or cross-referencing errors.

2.2.5. Turkish. Aksu-Koç and Slobin (1985) report that case distinctions on Turkish nouns are yet another of the early acquisitions made by children learning Turkish. They state that their subjects were using accusative case markers productively by the age of $2 ; 0$. They do not report whether the children made any case errors.

2.2.6. Kaluli. Kaluli, a non-Austronesian language spoken in Papua New Guinea, is one of the two languages I examined which uses an ergative morphological system. Schieffelin (1985) provides substantial data on the acquisition of the ergative case-marking system in Kaluli. Schieffelin states that Kaluli has an ergative case-marking system and an accusative pattern of verb agreement (1985: 591). When Kaluli speakers use the neutral AOV word order, the ergative-case marker is used for the $A$ only when both $\mathrm{A}$ and $\mathrm{O}$ are proper names or kinship terms; otherwise the $\mathbf{A}$ is marked with an optional neutral/absolutive-case marker (the neutral and absolutive case markers are homophonous). Kaluli puts focus on the agent of an action by placing the agent NP immediately before the verb; in this case the ergative case marker is obligatory with nonpronominal NPs.

Schieffelin recorded longitudinal samples from three children who were about 24 months old at the beginning of her study. Kaluli children start using ergative case markers between 26 and 30 months of age. By 32 months they appear to be using case markers appropriately in over half 
of their obligatory contexts. During this time the children sometimes used the neutral/absolutive case marker with As in preverbal position and overgeneralized the ergative case marker to all agents in AOV utterances, including pronouns. Schieffelin states that the absolutive was used with an agent in one of 77 tokens of OAV third-person utterances (1985: 560). The children apparently used the absolutive more frequently in AV utterances, although Schieffelin does not say how often this occurred. She does say that the children did not overgeneralize the ergative marker to actors of intransitive verbs (1985: 559).

In interpreting these data it is important to keep in mind that Kaluli is a pro-drop language. Schieffelin only collected $41 \mathrm{AOV}$ and 77 OAV third-person utterances in her entire corpus. Utterances consisting of a transitive verb and one argument occurred much more frequently and were fairly evenly split between AV and OV. Schieffelin does not provide any information on the first use of the absolutive marker, but she does say that the majority of agents have the neutral case marker in AV utterances (1985: 561). Once children discover the ergative case marker in AV utterances they seem to generalize it quickly to both AOV and OAV utterances. Finally, they learn to restrict the ergative case marker's use in AOV utterances to cases where both the $A$ and $O$ are proper nouns or kinship terms. The Kaluli data suggest that children initially apply the absolutive case to $\mathrm{S}, \mathrm{O}$, and $\mathrm{A}$ NPs, only later discovering the distinctive ergative marking for transitive subjects in the focus position.

Kaluli also contains two distinct sets of pronouns. One set, the focused form, is ergative in that it is only used to indicate an A. Like focused noun phrases, focused pronouns only appear in the focus position immediately before the verb. Their acquisition seems to be similar to that of focused noun phrases. Thus, Kaluli children initially use unfocused forms of both nouns and pronouns before using the focused forms which have an ergative type of restriction.

2.2.7. K'iche'. K'iche' has three sets of subject markers, as shown in (2), two for $\mathrm{A}$ and one for $\mathrm{S}$. The choice between the two ergative sets is conditioned by the initial phoneme of the verb root. A child learning $\mathrm{K}$ 'iche' has to distinguish between both transitive and intransitive verbs and between the allomorphic variants of the ergative set in order to use the subject markers successfully. Any confusion would be quite evident, particularly if the child used a prevocalic allomorph of the ergative set with an intransitive stem (for data on the acquisition of transitivity in K'iche', see Pye 1985). The homonymy between the ergative preconsonantal and absolutive first-person singular forms increases the likelihood that children would confuse the other ergative and absolutive subject markers. 
(2)

\begin{tabular}{|c|c|c|}
\hline \multirow[b]{2}{*}{ Singular } & Ergative: & Preconsonantal \\
\hline & & \\
\hline 1 & inw- & in- \\
\hline 2 & aw- & a- \\
\hline 3 & r- & u:- \\
\hline Plural & & \\
\hline 1 & q- & qa- \\
\hline 2 & iw- & i- \\
\hline 3 & $\mathrm{k}-$ & ki- \\
\hline
\end{tabular}

Table 2 provides the K'iche' data on subject-marker errors. The children range in age between $2 ; 1$ and 2;10 for Al Tiya:n, 2;9 and 3;1 for $\mathrm{Al}$ Cha:y, and 3;0 and 3;7 for A Carlos. In Table 2, an overextension of an ergative marker to an $\mathrm{S}$ was considered an error in the use of the ergative marker. The overextension of an absolutive marker to an $\mathrm{A}$ was counted as an absolutive error. As Table 2 shows, the children made only a small number of errors. Since these are critical data I have listed all of the children's errors in the Appendix.

One possible explanation for the low number of errors might be that the children were not yet using the person markers very frequently. To test this possibility, I counted the number of times the children used the subject markers and the proportion of times they were used in obligatory contexts. These data appear in Table 3. Table 3 shows that in samples 13-15, Al Tiya:n and Al Cha:y had begun to use the person markers in close to $20 \%$ of their obligatory contexts, while A Carlos used the person markers in half of their obligatory contexts for transitive verbs. Al Cha:y used subject markers 51 times with transitive verbs in sessions 13-15 while A Carlos used them 130 times. This would seem to have provided ample opportunity for errors if the children were going to make them.

At this point it is necessary to decide whether the errors shown in

Table 2. Frequency of subject-marking errors in K'iche'

\begin{tabular}{cllllll}
\hline Session & \multicolumn{2}{c}{ Al Tiya:n } & \multicolumn{2}{c}{ Al Cha:y } & \multicolumn{2}{c}{ A Carlos } \\
& abs & erg & abs & erg & abs & erg \\
\hline $1-3$ & - & - & - & - & - & - \\
$4-6$ & - & - & 2 & 1 & - & - \\
$7-9$ & - & - & 1 & - & - & 5 \\
$10-12$ & - & - & 2 & - & - & 1 \\
$13-15$ & 1 & - & - & - & - & 1 \\
$16-18$ & & & 1 & 1 & 2 & 1 \\
$19-21$ & & & - & - & - & - \\
\hline
\end{tabular}


Table 3. Frequency and percentage presence in obligatory contexts of subject markers on K'iche' verbs'

\begin{tabular}{|c|c|c|c|c|c|c|c|c|c|c|c|c|}
\hline \multirow[t]{2}{*}{ Session } & \multicolumn{2}{|c|}{$\begin{array}{l}\text { Al Tiya:n } \\
\text { Ivs }\end{array}$} & \multicolumn{2}{|l|}{ Tvs } & \multicolumn{2}{|c|}{$\begin{array}{l}\text { Al Cha:y } \\
\text { Ivs }\end{array}$} & \multicolumn{2}{|l|}{ Tvs } & \multicolumn{2}{|c|}{$\begin{array}{l}\text { A Carlos } \\
\text { Ivs }\end{array}$} & \multirow{2}{*}{$\begin{array}{l}\text { Tvs } \\
\text { no. }\end{array}$} & \multirow[b]{2}{*}{$\%$} \\
\hline & no. & $\%$ & no. & $\%$ & no. & $\%$ & no. & $\%$ & no. & $\%$ & & \\
\hline $1-3$ & 6 & 86 & 9 & 39 & - & - & 3 & 2 & 19 & 50 & 17 & 71 \\
\hline 4-6 & 3 & 50 & 5 & 11 & 9 & 39 & 10 & 4 & 20 & 67 & 63 & 50 \\
\hline $7-9$ & 4 & 31 & 6 & 10 & 5 & 22 & 12 & 6 & 31 & 58 & 128 & 46 \\
\hline $10-12$ & 6 & 38 & 19 & 17 & 3 & 7 & 48 & 16 & 17 & 65 & 152 & 54 \\
\hline $13-15$ & 4 & 10 & 25 & 19 & 2 & 9 & 51 & 18 & 31 & 70 & 130 & 51 \\
\hline $16-18$ & - & - & - & - & 14 & 50 & 76 & 33 & 24 & 70 & 149 & 69 \\
\hline $19-21$ & - & - & - & - & 19 & 59 & 64 & 43 & 23 & 80 & 87 & 71 \\
\hline
\end{tabular}

Table 2 are true overgeneralizations or the product of lapses in memory or attention on the part of the children. In other words, do these errors reveal anything about the children's linguistic competence or merely their performance? I addressed this issue by determining how frequently the children overgeneralized the person markers. A Carlos's errors represent $3 \%$ of the total person-marker usage in samples 7-9 and $1 \%$ of the total in samples 13-15. In the later samples, Al Cha:y and A Carlos erred on $1 \%$ of the subject markers they produced. Tables 2 and 3 suggest that $\mathrm{K}$ 'iche' children begin occasionally to extend the ergative person markers to intransitive verbs when they are using the person markers in about half of their obligatory contexts. I have no data to show when the K'iche' children cease overgeneralizing the ergative markers, although such errors are absent in my samples of adult speech. There is no indication that the acquisition of one set lags significantly behind that of the other.

Many of the errors in Table 2 are probably due to a lack of attention or inability to produce every part of the K'iche' sentence. The independent pronouns in K'iche' are identical in form to the absolutive set of person markers with the exception of the third-person singular and plural forms. Up to the age of 36 months the children, and especially Al Cha:y, sometimes used independent pronouns instead of person markers to indicate what they were talking about. The flexible word order in K'iche' allowed the children to use subject pronouns in a preverbal position. Since they were not using the aspect and person markers on the verb, the resulting construction appears to be an overgeneralization of the absolutive forms to transitive verbs. The use of independent pronouns accounts for most of the apparent absolutive overextensions in the children's data.

A variety of factors appears to be at work in the other examples. Example 11 from Al Cha:y (in the Appendix) may be the result of 
dropping the final consonant of the person marker in anticipation of the following sound. Example 15 from A Carlos appears to be a simple case of metathesis: he produced ustinik instead of sutinik.

This still leaves examples 9 and 10 from Al Cha:y and examples 12, 13, 14, and 18 from A Carlos as genuine instances of person-marker overgeneralization. Examples 9 and 18 are instances of overgeneralizing an absolutive marker to transitive verbs, while examples $10,12,13,14$, and 16 are overgeneralizations of ergative markers to intransitive verbs.

In sum, the data indicate that K'iche' children occasionally use absolutive subject markers with transitive verbs and ergative subject markers with intransitive verbs. Although this evidence is scanty, its frequency is in reasonable agreement with other reports of the frequency of morpheme overgeneralization. There is no evidence to suggest that the acquisition of either the ergative or the absolutive sets of cross-reference markers lags significantly behind the other.

2.3.4. Summary of the data on the acquisition of morphology. I have identified a number of errors that occur in children's use of ergative and accusative morphology. Children's acquisition of this morphology is relatively error-free, with the exception of the English pronouns, German articles, and Kaluli focused NPs. These data support the distinction I made above between closed-class and open-class morphology in that the English pronouns and German articles constitute closed-class lexical items. It is especially interesting in this regard that English-speaking children produce more overgeneralizations with pronouns than with verb agreement, while German-speaking children have more difficulty with articles than with adjectives. I will argue in section 3.2.2 below that Kaluli contains an ergative syntactic system rather than an ergative morphological system. The fact that focus is a syntactic operation that operates on ergative principles in Kaluli accounts for Kaluli children's frequent errors.

The acquisition data that are presently available suggest that children have no initial bias to extend subject markers in any particular way based upon an underlying semantic relation. Table 4 presents a summary of the types of extensions in children's acquisition data. The infrequency of these errors in the data for Japanese-, K'iche'-, Polish- and Turkishspeaking children, and the inconsistencies in the directions of the extensions, indicate that these are performance overgeneralizations rather than competence overgeneralizations. In contrast, the Kaluli AV errors and English pronominal extensions are more frequent and more consistent. These are the sorts of extensions that would be expected if the children had systematically misanalyzed the case system of the adult language. 
Table 4. A summary of morphological extensions found in the acquisition of morphologically ergative and accusative languages

\begin{tabular}{lll}
\hline Extension & $\begin{array}{l}\text { Initial morphology } \\
\text { accusative }\end{array}$ & ergative \\
\hline $1 . \mathrm{S} / \mathrm{O} \rightarrow \mathrm{A}$ & & Kaluli (AV), perhaps K'iche' \\
$2 . \mathrm{A} / \mathrm{S} \rightarrow \mathrm{O}$ & German, Japanese & K'iche' \\
$3 . \mathrm{A} \rightarrow \mathrm{S}$ & English & \\
$4 . \mathrm{O} \rightarrow \mathrm{S} / \mathrm{A}$ & & \\
\hline
\end{tabular}

\section{Syntactic ergativity}

Up to this point, I have assumed that the languages I have been examining have syntactic structures that are basically the same as those in English. That is, the A NP is the grammatical subject and the O NP is the grammatical object. However, it is logically possible to envisage a language with the opposite mapping between semantic roles and syntactic positions. Such a language would insert A NPs into the grammaticalobject position and S or O NPs into the grammatical-subject position. This would be an example of a language that was syntactically ergative, since its syntactic subjects would consist of $S$ and $O$ NPs while its syntactic objects would be A NPs. A language which is syntactically ergative in its entirety would have the phrase structure shown in (3) for basic sentences with transitive verbs (see Dixon 1972; Marantz 1984).

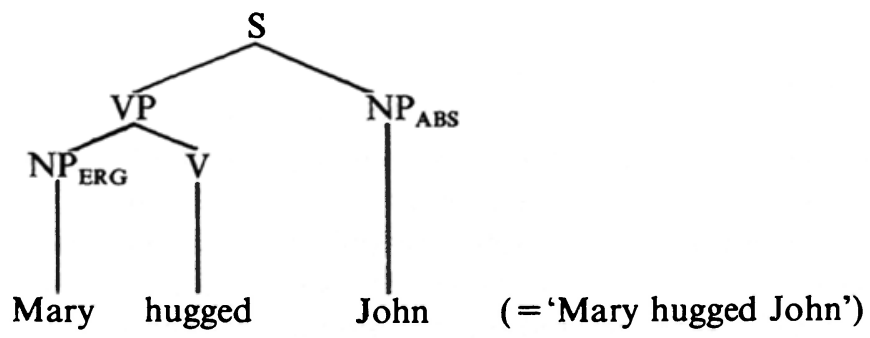

A number of linguists have claimed that there are languages which exhibit an ergative syntactic structure (see Dixon 1972; Woodbury 1977). This claim, however, remains extremely controversial, and alternative explanations of syntactically ergative constructions have been proposed (see DuBois 1987; Gabelentz 1860; Hale 1970; Postal 1977). More recently, Marantz (1984) adopted the ergative syntactic structure as the core of his ergativity hypothesis. This hypothesis states that syntactically ergative languages exist and that they have an underlying syntactic structure like the one in (3). 
Marantz derived a number of predictions about syntactically ergative languages on the basis of the ergativity hypothesis combined with his theory of syntactic relations (a version of Chomsky 1981; see also Levin 1983). For example, if $S$ and $O$ are the syntactic subjects in a syntactically ergative language then a 'passive' rule would promote an $A$ to the subject position, while the $O$ might appear in an optional oblique phrase. This is precisely what results from the application of the antipassive a syntactic operation typical of ergative languages. Examples of active, passive, and antipassive sentences in K'iche' are shown in (4). The transitive verb becomes intransitive in the antipassive (it has only a single agreement marker) and the $O$ is relegated to an optional oblique phrase.

(4) a. Active:

k-0-u-yoq' le: alah

INCOMP-3A-3E-mock the boy

'He mocks the boy.'

b. Passive:

k-0-yo:q'

le: alah (r-uma:l)

INCOMP-3A-mock (PASS) the boy (3E-because)

'The boy is mocked (by him).'

c. Absolutive antipassive:

k-0-yoq'-on

(che: le: alah)

INCOMP-3A-mock-ABS (at the boy)

'He mocks (at the boy).'

Marantz also predicts that reflexivization will behave differently in syntactically ergative and accusative languages. Some languages add a reflexive morpheme to transitive verbs to indicate a reflexive action rather than using a reflexive pronoun as English does. According to Marantz, a reflexivized verb becomes intransitive and assigns a semantic role $\mathrm{O}$ to the single lexical NP in the sentence. The verb is therefore structurally similar to a passivized verb and receives a similar interpretation. Marantz observes that passive and reflexive verb forms are homophonous in most languages. He predicts that such sentences are also ambiguous in syntactically ergative languages. However, the ambiguity would be between reflexive and antipassive readings. This is because the semantic role of the subject of an antipassive sentence in an ergative language is $A$ rather than $\mathbf{O}$.

Marantz (1984: 212) cites such an example from Dyirbal, repeated in (5). Dyirbal uses the affix -riy-to form the reflexive form of a transitive verb. The Dyirbal sentence in (5) is ambiguous in the predicted manner. 
(5) bayi yara buybayirnu

man-ABS hides-REFL

'Man hides himself' or 'Man hides (something).'

K'iche' provides another example of an antipassive-reflexive ambiguity. The antipassive construction in (6) has both antipassive and reflexive interpretations. Mondloch (1981: 196-197) gives several additional examples.
k-0-ch'aj-an
le: ak'al

INCOMP-3A-wash-ABS the child

'The child is washing himself' or 'The child is washing (something).'

Marantz's most striking prediction concerns the control properties of verbs in syntactically ergative languages. In accusative languages the subject of the embedded clause is always the NP that is controlled by an NP in the matrix clause. When control of an object NP is attempted, as in (7), the result is ungrammatical.

*Henry wants Jennifer to take

Syntactically accusative languages use either pronouns or passivized clauses to express this notion.

(8) a. Henry wants Jennifer to take him.

b. Henry wants to be taken by Jennifer.

Marantz's ergativity hypothesis predicts that in a syntactically ergative language the O NP should be controlled since it is the subject of an embedded clause. This is exactly what occurs in Yup'ik Eskima (Reed et al. 1977, cited in Levin 1983). Yup'ik has a set of verbal postbases which correspond to English verbs with control complements. The verb to which the postbase is suffixed is understood as an embedded verb. The Yup'ik postbases are transitive; the controller is the absolutive argument of the postbase. Levin (1983: 127, example 3.59) cites the following example from Reed et al. as evidence that the absolutive NP in Yup'ik is controlled. In (9) the absolutive argument qimugta is interpreted as 'the one taken' rather than 'the taker'.

Anucetaa qimugta.

take outside-let-INDIC-3s/3s dog-ABS

'He lets the dog be taken outside.'

The Australian aboriginal language Dyirbal also displays this property. Levin (1983: 262, example 5.58) cites the Dyirbal purposive complement 
clause as evidence. In (10) the absolutive argument bayl yara is the one pointed out, not the one doing the pointing. In ergative terms, the unexpressed subject of the embedded purposive clause has the same referent as the subject of the matrix clause.

bayl yara waynyjin yalu banggun dundunggu
There-A man-A go uphill-NFUTto here there-E bird-E
manjali
point out-PURP

'Man came uphill toward here, resulting in bird's pointing out his presence.'

This prediction cannot be tested in K'iche' since there is no infinitival form of the verb with which to test it. Instead, K'iche' uses either finite or nominalized verb forms in complement clauses. The nominalized forms optionally take possessive prefixes to indicate the participant. The participant can be either an $\mathrm{O}$ or an $\mathrm{A}$, depending on whether the passive or antipassive nominalization was used.

To summarize, there would appear to be substantial evidence for Marantz's ergative hypothesis. Dixon (1979), however, argues that all languages group $\mathrm{A}$ and $\mathrm{S}$ together for certain purposes. All languages group $A$ and $S$ together as the addressee in imperative sentences (although some languages restrict the types of Ss which can occur in the imperatives of sentences with intransitive verbs). Languages also group $\mathrm{A}$ and $\mathrm{S}$ together as the controlled NPs in sentences involving such verbs as can, begin, must, try, and want. For example, in the sentence 'John tried to feed Sarah', John is understood to be the one trying to carry out the action and the one feeding Sarah. All of these verbs have the semantic property that their subject is identical with the $A$ or $S$ of the verb in the embedded clause. Finally, the presence of a regular passive construction in addition to the antipassive in some ergative languages raises complications for Marantz's hypothesis (see Postal 1977).

In light of these considerations, Dixon rejects an underlying structure such as that shown in (3) above and proposes instead that all languages have an underlying structure that is syntactically accusative. He speculates that languages may group semantic roles together as a syntactic 'pivot' in various ways. Dixon notes that languages differ in the degree to which either $\mathbf{A}$ or $\mathbf{O}$ is grouped with $\mathbf{S}$ for syntactic purposes (Foley and Van Valin 1984 present a detailed discussion of the cross-linguistic diversity associated with syntactic pivots). Dixon's proposal predicts that languages may display a range of syntactically ergative constructions rather than the all-or-nothing effect of Marantz's proposal.

Neither Marantz nor Dixon considered the learnability issues that arise 
in connection with syntactically ergative languages. In section 3.1 , I will show that syntactically ergative languages in the sense of Marantz's ergativity hypothesis are unlearnable. Languages may have constructions which exhibit syntactically ergative properties, but these are best described as syntactic pivots in Dixon's sense rather than as reflections of a thorough-going ergative syntactic structure. The learnability argument predicts that children will have great difficulty acquiring the types of syntactically ergative constructions Marantz used to support his hypothesis. In section 3.2, I provide some acquisition data which suggest that children do have a much more difficult time learning syntactically ergative constructions than they do learning ergative morphology.

\subsection{The learnability of syntactically ergative languages}

The existence of syntactically ergative languages in the sense proposed by Marantz would create severe learnability problems. Children would have to decide at some point whether the language they are learning is syntactically ergative or accusative. This means they would have to discover which NP in a transitive clause is the subject.

Children could not rely upon the morphological encoding of syntactic relations to do this (although Pinker 1989 argues that morphology alone would be sufficient). It is true that languages with syntactically ergative constructions have at least partially ergative morphologies (that is, they use the same markers for $\mathbf{S}$ and $\mathrm{O}$ ). However, there are languages like K'iche' which, even though they have an ergative morphology, are syntactically accusative. Dixon (1979: 125) states that in fact the majority of morphologically ergative languages have an accusative syntax. Dyirbal is close to the opposite extreme. It meets or exceeds all of Marantz's tests for syntactic ergativity and yet it is morphologically accusative in the first and second persons. A child using morphology as a guide to syntax would mistakenly assume that $\mathbf{K}$ 'iche' was syntactically ergative and might assume that Dyirbal was syntactically accusative.

Levin (1983) and Dunn (1987) suggest that syntactic ergativity may be the product of restrictions on case assignment. Levin (1983: 70) notes that Stowell's adjacency requirement on case assignment (Stowell 1981) would predict an interaction between word order and syntactic ergativity. Stowell's adjacency requirement requires the object to be adjacent to the verb in order to be assigned case. For a language with syntactic ergativity, this would mean that the ergative NP (A) would have to be adjacent to the verb. Children could combine information about word order and semantic roles to decide the syntactic type of their language. If the 


\section{C. Pye}

language had the order OAV it would be ergative, while if the language had the order AOV it would be accusative.

Such a solution could only work for verb-initial and verb-final languages. An ergative language with AVO word order would be unlearnable since children could not rely upon adjacency to decide whether the language was ergative or accusative. The hypothesis is more directly contradicted, however, by the existence of a number of well-documented languages that are syntactically accusative even though they have VAO word orders. Welsh (Sproat 1983) and Jacaltec Mayan (Craig 1977) are just two examples. The order of semantic roles, therefore, is not a reliable guide to a language's syntactic type.

Reflexive verb forms would provide another means of determining whether the simple clause is syntactically ergative. It goes without saying that in order to apply this test the language would have to have a reflexive verb form. Marantz and Levin cite reflexive verb forms from Dyirbal and Yup'ik Eskimo to support their argument (see example [5] above). The Yup'ik examples are identical to the antipassive verb forms. Syntactically accusative languages like K'iche' also have antipassive verb forms with reflexive interpretations (for example, ch'aj-an 'wash' and suti-n 'spin'). Once K'iche' children learned these forms, they might conclude, incorrectly, that K'iche' was a syntactically ergative language. This proves that the existence of antipassive verbs with reflexive interpretations does not guarantee that the language is syntactically ergative.

One of the best known explanations of how children establish grammatical relations is the semantic bootstrapping hypothesis, as proposed in Grimshaw (1981) and Pinker (1984). However, semantic bootstrapping would lead children to exactly the wrong conclusion for syntactically ergative languages in the sense of Marantz's ergativity hypothesis. When exposed to such simple sentences in Dyirbal as (11), children would simply assume that banggun dugumbiru is the subject. This assumption would receive massive confirmation from the other simple, active sentences in the input so that the 'subject=ergative NP' rule would become well entrenched in the children's grammar.

Dixon (1972: 76)

balan buni banggun dugumbiru mabali

there-abs fire-abs there-erg woman-erg light

'Woman lit fire.'

This would lead to a number of errors in the child's later grammatical development. For example, Dyirbal children would be unable to interpret sentences with purposive complement clauses such as (12) correctly. 
(12) Dixon (1980: 458)

balan jugumbil miyanda + nyu banggul yara + nggu

she + ABS woman + ABS laugh + PAST he + ERG man + ERG

bura + li

see + PURP

'The woman laughed and was (as a result) seen by the man.'

Finally, Dyirbal children would interpret sentences with verbal reflexives such as (13) as having an additional PASSIVE rather than an active transitive meaning.

$$
\begin{aligned}
& \text { Dixon (1972: 90) } \\
& \text { bayi yara buyba + yiriy + nyu } \\
& \text { he + ABS man + ABS hides + REFL } \\
& \text { 'Man hides himself' or 'Man hides (something).' }
\end{aligned}
$$

In short, the syntactic structures Dyirbal children initially construct on the basis of semantic bootstrapping would lead to considerable difficulties in their use of the more complex ergative syntactic constructions. Childlanguage observers should find a considerable amount of evidence that children acquiring syntactically ergative languages had picked the wrong noun phrase as subject.

Children could still use semantic bootstrapping to acquire syntactically ergative languages if they had some way of undoing their mistakes. However, a child would not be able to identify the nature of the error, let alone correct it, solely on the basis of positive evidence. I will assume that children do not rely upon some form of negative evidence (such as correction from adults) to correct their mistake (see Pinker 1989 for arguments against invoking negative evidence).

Correcting such mistakes requires that children realize that in order to stop misinterpreting infrequent syntactic constructions, they must make a wholesale shift in the way they assign semantic roles to syntactic positions. There is no reason to assume that children would entertain such a drastic revision in their grammar when more restricted changes in their rules would enable them to deal with each exception on an individual basis. It would be far easier for children to implement a locally efficient solution than to discover the maximally efficient grammar. Some further principle would be necessary to compel children to associate reflexives, purposive clauses, and antipassives in a systematic fashion.

For example, when a Dyirbal child successfully understands a sentence with a purposive clause (such as [12], 'Woman-abs laughed man-erg seePurposive'), he might interpret the purposive inflection as a type of passivizing morpheme. Note that a passive translation in English ('The 
woman laughed and was seen by the man') is much more acceptable than one using the active voice (*'The woman laughed and the man saw'). A passive-voice interpretation would save the specified-subject constraint, which allows only subjects to be missing in verb-complement clauses but miss the fact that the absolutive NP is the subject of an active clause, not a passive one. Since the verb has the purposive inflection, the child would need some way of distinguishing between purposive and passive inflections in order to learn the appropriate interpretation of such sentences. Indeed, a further possibility would be to interpret this inflection as a passive with an additional purposive implication. Passives in Japanese add an adversative reading, while passives in Salish languages can indicate a lack of agent control (Dale Kinkade, personal communication). I do not see any way in which a child could resolve this issue solely on the basis of contextual evidence.

Dyirbal children would also be exposed to conjoined sentences with antipassivized clauses, but they might conclude that Dyirbal contained a rule requiring case agreement between clauses rather than a universal rule of subject deletion. Dyirbal children could learn to form antipassives by changing the marking on the ergative NP to absolutive while deleting the original absolutive NP and making the appropriate change in the verb's morphology. This would allow acquisition of antipassive sentences but would not alter the underlying grammatical relations the children have constructed using semantic bootstrapping.

Thus, in every case where children would find potential evidence for syntactic ergativity, there are other possible interpretations of the data that would require fewer changes in the structure of their grammar AT ANY SINGLE POINT IN TIME. These localized 'fixes' would lead to appropriate grammatical productions but miss the generalizations that underlie Marantz's ergativity hypothesis - the uniform syntactic properties of subjects.

\subsection{Acquisition data}

3.2.1. K'iche'. The K'iche' children's use of person markers on verbs suggests that their acquisition of an ergative morphology is remarkably accurate. K'iche' also has some features of a syntactically ergative language, the most important of which is a restriction on accessibility in questions, relative clauses, and focus constructions. Keenan and Comrie (1977) show that subjects may be easier to question than objects, but not vice versa. In K'iche', an A NP cannot be questioned directly; instead the verb must be changed to the focus antipassive form. S and O NPs, 
on the other hand, are questioned without changing the morphological form of the verb stem. This would indicate that the S and O NPs in $\mathrm{K}$ 'iche' are the 'subjects' in questions. For example, one of my K'iche' assistants asked the following questions of $\mathrm{Al} \mathrm{Cha:y:}$

$\begin{array}{lll}\text { jas } & \text { k-0-u:-b'an } & \text { le: patax } \\ \text { what } & \text { INCOMP-3A-3E-do the duck }\end{array}$

'What is the duck doing?'

jachi:n x-0-ya'-ow le: su't chi-aw-e:ch

who COMP-3A-give-FA the cloth to-2E-possession

'Who gave the cloth to you?'

The first question asks about the $\mathrm{O}$ and is in the active voice, whereas the second question asks about the $\mathrm{A}$ and is in the focus antipassive voice. When the focus is on an A (the ergative NP) in questions, the A is 'promoted' to an S. The objects of transitive verbs and subjects of intransitive verbs do not require special treatment. In this respect, $K$ 'iche' behaves like a syntactically ergative language $(O$ is more accessible than A).

I searched the K'iche' transcripts for examples of the children's productions of subject-focus constructions. I have discovered that none of the children produced unequivocal examples of focus antipassive verbs even though they were using verbs in a variety of nonactive voice forms (Pye and Quixtan Poz 1988). The following examples illustrate the ways in which $\mathrm{K}$ 'iche' children failed to supply the focus antipassive in obligatory contexts.

(16) $\mathrm{S} 2-50$

Al Tiya:n (age 2;1.17)

Adult 1 jachin xya'-ow chaweh?

who gave-FA it to you?

Tiya:n jah?

what?

Adult 1 jachin xya'-ow chawech, jah? who gave-FA it to you, huh?

Adult 2 mu's katcha'. the ladino you say.

Adult 1 dih.

dear.

Tiya:n jah?

what?

Adult 1 jachin ya'-ow lawetz'ab'al?

who gave-FA your toy?

Tiya:n no', at o (=no' at xatya'-ow-ik).

no, you gave it. 
In this conversation Adult 1 asks $\mathrm{Al}$ Tiya:n several times who gave her toy to her, using the focus antipassive construction. After several attempts Al Tiya:n finally responds by saying that Adult 1 gave it to her. Her response answers the question, but reduces the verb 'give' to a single vowel $-o$. This would be the appropriate termination for the transitive form of this verb in sentence-final position $\left(-y a^{\prime}-o h\right)$. However, this is a context in which the focus antipassive suffix is required.

(17) Rl-31 Al Cha:y (age 2;9)

Adult 1 jachin xkoj-ow le: wari cho'qoq. who used-FA this say.

Cha:y no.

no.

Adult 2 cha:y cha, jachin xkoj-ow lachachal katcha.

Cha:y he says, who used-FA your necklace you say.

Cha:y no.

no.

Adult 2 uy, chab'ij k'ut chare:, are: le: nuna:n katcha chare:.

uy, say it to him, it is my mother you say to him.

Cha:y no, koj taj in (= no ma xinkoj-ow taj). no, I did not use it.

Here $\mathrm{Al}$ asks $\mathrm{Al}$ Cha:y who used a necklace, using the focus antipassive construction. When $\mathrm{Al}$ Cha:y refuses to respond, A2 repeats the question to Al Cha:y and even supplies her with an answer. Al Cha:y, however, refuses to cooperate and responds by saying that she did not use it. She has picked out the proper verb root but uses the active rather than focus antipassive verb form.

$$
\begin{array}{ll}
\text { R18-18 } & \text { Al Cha:y (age 3;3.14) } \\
\text { Cha:y } & \begin{array}{l}
\text { jachin ya'-oh bay chupam } \\
\text { who give-TTV rock inside } \\
\text { (= jachin xya'-ow le: ab'aj chupam) }
\end{array} \\
\text { 'who put the rock inside it?' } \\
\text { Adult } 1 & \begin{array}{l}
\text { chin chike' } \\
\text { which one? }
\end{array}
\end{array}
$$

Al Cha:y asked this question in the middle of a conversation about doll clothes. She turned to other matters when no one responded to her question. It shows that she was willing to use the verb $-y a$ with a regular transitive termination in a context which would require the focus antipassive suffix -ow. 
A Carlos was the only K'iche' child who seemed to use focus antipassive verb forms. When he did use them, he made mistakes which indicate that he had not mastered this verb form completely. The following extract shows A Carlos using the focus antipassive form to emphasize who was responsible for giving him the toy. However, A Carlos uses an ergative rather than absolutive cross-reference marker, an indication that he did not recognize that the focus antipassive form was an intransitive verb.

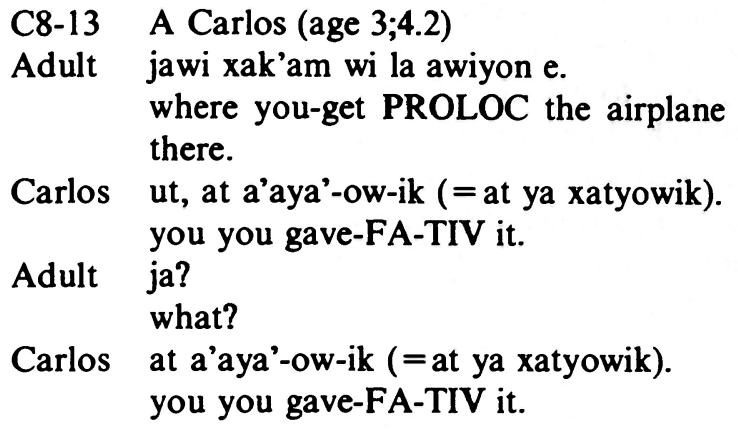

Later in the same transcript, A Carlos used another verb in the focus antipassive form in an inappropriate fashion. This excerpt is shown below:
C8-15
A Carlos (age 3;4.2)
Adult
ma kinkowin ta chik.
I can not again.
Carlos t'o-ow-ik cha', we'i ti'ik cha'.
it help-FA-TIV he says, mine was bitten he says
( $=$ are xtowik cha', le we in xti'ik cha').

In this case, I am not certain whether A Carlos meant to use the focus antipassive form of the ver -to 'to help' or the passive form of the verb $-t i$ ' 'to bite'. If he did mean to use the focus antipassive form, he omitted the focused constituent that this verb form requires.

These data suggest that K'iche' children have more difficulty with the focus antipassive construction than with either the passive voice or the absolutive antipassive voice. K'iche' children initially use active forms of transitive verbs in contexts where the focus antipassive form is obligatory. They begin using focus antipassive verb forms as early as three years but continue to have difficulty coordinating the use of the verb form with the appropriate cross-reference markers and focused constituents. Positive evidence is available to $\mathrm{K}$ 'iche' children from adult subject-focus utterances. Such utterances enable K'iche' children to note the obligatory use of the focus antipassive construction in particular contexts and add this 
rule to their grammar. This is far different from the wholesale restructuring of the basic phrase-structure rules that the children would face if they were learning a syntactically ergative language.

3.2.2. Kaluli. The discussion of the K'iche' children's acquisition of the focus antipassive construction puts the Kaluli children's struggle with the ergative case markers and pronouns in a new light. The ergative case markers and pronouns in Kaluli are used to focus on an A NP in much the same way that the K'iche' focus antipassive construction does. Subject-focus constructions do not alter the form of the verb in Kaluli, but they do require that children note that the language treats focused As differently from focused Os and Ss. From this perspective, the Kaluli treatment of focused As provides another example of an ergative syntactic construction, rather than a simple ergative morphology. The children's initial use of absolutive case markers with focused As takes on a new significance in this light. The children's use of the absolutive forms indicates that they have assimilated the focused A constructions to an otherwise accusative syntactic pattern. The Kaluli children have positive evidence from the adult language of just what the restrictions on focusing are, and they eventually use the appropriate case marking and pronoun forms. However, they can add such restrictions to their initial grammar without having to restructure its basic phrase structure.

3.2.3. Bennish. My discussion of the learnability of morphological ergativity hinted that there is no reason to expect children learning morphologically ergative languages to make more mistakes than children learning morphologically accusative languages. The description of a language termed 'Bennish' (Sadock 1982) suggests that it is possible for children learning English to impose an ergative system on some syntactic features of the language as well. ${ }^{5}$

Between 20 and 24 months Jerrold Sadock's son Ben had an optative mood with markedly ergative features. One characteristic of this mood was that subjects of intransitive clauses occurred in the same position as the objects of transitive clauses. Sadock (1982: 187) gives the following examples of intransitive clauses in the Bennish optative:

(21) Fall down Daddy. 'Daddy should fall down.'

(22) Eat Benny now. 'Let Benny eat now.'

Although Sadock states that such sentences may have arisen from imperative models with a postposed vocative (such as 'Sit down, Ben'), 
he gives two reasons why Ben's optatives were not imperatives. First, the optatives did not require addressee subjects. They could contain both a subject and a vocative, as in the following example:

(23) Sit down Maggie, Mommy.

'Maggie should sit down, Mommy.'

Second, subjects in optative clauses received regular stress whereas the vocatives were part of a separate stress group.

Transitive clauses in the optative mood underline the ergative nature of the system. Sadock gives the following examples:

(24) Pick up Benny for Daddy. 'Daddy should pick Ben up.'

(25) Read a story for Mommy. 'Mommy should read a story.'

(26) Erase it for Daddy. 'Daddy should erase it.'

In transitive clauses the object occurs in the same position as the subject of intransitive clauses. The subject of transitive clauses, however, has what might be construed as an ergative marker - the preposition for.

At this stage Ben also had a productive rule of verb-particle reduplication which further underscored the ergative nature of his optative mood. In Ben's language, particle reduplication served an emphatic function; for example,

(27) Pick up Benny up for Daddy.

'Daddy must pick Ben up!'

Particle movement in adult English only occurs over the object of transitive verbs, but in Bennish particle reduplication occurred with the subjects of intransitive verbs as well:

Wake up Daddy up!

'Daddy must wake up!'

Optative clauses also occurred as infinitival complements to main clauses with the verb want. Their meaning was similar to the meaning of the main-clause optatives:

(29) I want to sit down Maggie.

'I want Maggie to sit down.'

(30) I want to hold him for Mommy.

'I want Mommy to hold him' (that is, Ben).

The Bennish optative is interesting for several reasons. First, it shows how wrong children can go in reconstructing the adult grammar. Ben 
apparently overgeneralized from examples of imperative sentences with vocatives to create a novel system for expressing the optative mood. Second, Ben's overgeneralization was restricted to just the optative mood. Although Dixon does not note any adult languages with ergativity restricted by mood, there are languages which restrict ergative constructions to particular tenses or aspects. Even though the Bennish optative is not a part of adult English it does seem to be a possible feature of human languages.

The evidence from Ben's word-order patterns and particle reduplication suggests that in his optative constructions Ben had overgeneralized the treatment of transitive verb objects to the subjects of intransitive verbs. Assuming that this was the case, this overgeneralization suggests that Ben had reanalyzed Ss as the grammatical objects of intransitive verbs in the optative mood (rather than reanalyzing Os as grammatical subjects). This is a logical possibility that Marantz and other linguists have overlooked in their descriptions of syntactically ergative languages.

Linguistic theory currently distinguishes between the Ss of intransitive verbs which have a patient type of semantic role and Ss which have an actor type of semantic role. The former are referred to as 'unaccusatives', while the latter are known as 'unergatives' (see Perlmutter 1989). Intransitive verbs such as break, fall, and spin are typical unaccusative predicates since the NPs that appear with them do not initiate or control the action denoted by the verb. Dixon notes that many languages use morphology to assimilate the Ss of unaccusative verbs with the Os of transitive verbs. However, he does not mention any languages that assimilate all Ss with Os as syntactic objects.

\subsection{Summary of syntactically ergative acquisition data}

I have discussed acquisition data for ergative syntactic constructions in $\mathrm{K}$ 'iche' and Kaluli. The constructions in both languages involve syntactic restrictions on focus operations that treat the As of transitive verbs differently from Os and Ss. The K'iche' and Kaluli children experienced more difficulties learning ergative syntactic restrictions than children do learning morphological systems, whether ergative (K'iche') or accusative (German, Japanese, Polish, and Turkish). This data supports the prediction from the semantic-bootstrapping hypothesis that children begin with an accusative syntactic structure.

I included the data on Bennish as an example of how children can go wrong in acquiring as thoroughly an accusative language as English. While Ben's data contradict the semantic-bootstrapping hypothesis to a 
certain extent, there are features of the data that make the example less than compelling. The restriction of the phenomenon to the optative mood, although similar to morphological restrictions in morphologically ergative languages, has not been observed in syntactically ergative constructions. It also seems that Ben's optative constructions are not syntactically ergative in the sense of Marantz's ergativity hypothesis. Rather, they may have resulted from the assimilation of Ss to Os in a manner that is more typical of ergative morphology (see Dixon's [1979] discussion of 'split-S' and 'fluid-S' languages). In the final section of this paper I will discuss the implications of these data for acquisition theory and the ergativity hypothesis.

\section{The acquisition of ergative languages}

The available data on the acquisition of ergative languages are robust enough to constrain acquisition theory and actually support some of the proposals. In this section I will discuss which proposals are supported by the data and propose an additional hypothesis of my own.

\subsection{Morphological ergativity}

Acquisition data from a number of languages support a distributionallearning account of the acquisition of ergative and accusative morphology. Children seem to acquire an ergative or accusative morphology with equal ease and great accuracy. They use ergative and accusative markers with the subjects of both transitive and intransitive verbs. There is no indication that children will first use the ergative or accusative markers before the absolutive or nominative markers. At some later point (when children are using subject markers in $50 \%$ or more of their obligatory contexts), they begin to systematize more general inflectional rules that are abstracted from the lexical inflection patterns. At this point, children may overgeneralize an inflection to an inappropriate noun or verb. However, their overgeneralizations remain infrequent, generally less than $10 \%$ of all inflections, indicating that their overgeneralizations reflect performance factors rather than misanalyzed inflectional rules.

A number of researchers have postulated acquisition accounts that fit this description, beginning with Cazden (1968) and extending through MacWhinney (1978) to Maratsos and Chalkley (1980). I would add that it remains to tighten such an account sufficiently to predict the number of inflected lexical items necessary to trigger the formation of a general 
inflectional rule, as well as the strength of such a rule once it is formulated - that is, to be able to predict the frequency of overgeneralization based on the strengths of competing inflectional rules. Bybee and Slobin (1982) take a step in this direction with respect to past-tense paradigms, but clearly future research requires more careful documentation of the frequency of morpheme overgeneralization as well as the number of words appearing with particular inflections.

There is also some support for the idea that distributional learning is more effective for inflections that occur with members of open lexical classes. The acquisition data suggest that children have more difficulty with the case distinctions on English pronouns and German articles than they do with the case distinctions on German adjectives and Polish nouns and the cross-reference markers on K'iche' verbs. Maratsos and Chalkley make a special note of the fact that inflectional rules will be strengthened by the number of words that use a particular inflection. This observation is supported by the acquisition data discussed here.

The acquisition of case and cross-referencing morphology, however, highlights a significant problem for the distributional-learning account. Human languages limit their cross-referencing and case morphologies in various ways. There do not appear to be any human languages, for example, which use one set of markers for $A$ and $O$ while using a different set of markers for $\mathbf{S}$. A distributional-learning model is capable of learning these systems as easily as any ergative or accusative system. Thus, distributional learning cannot account for the restrictions on morphological systems found in human languages. There may be other factors that are responsible for these restrictions (DuBois 1987 suggests that the flow of information in discourse restricts these systems). However, until such factors are described in detail, distributional-learning accounts will remain less than satisfactory.

\subsection{Syntactic ergativity}

In section 3.1, I argued that syntactically ergative languages in the sense of Marantz's ergativity hypothesis were unlearnable. I showed that there is no unambiguous evidence that would tell children that a particular language is syntactically ergative. However, there are syntactic constructions in some languages which group the $\mathrm{S}$ and $\mathrm{O}$ together as a syntactic pivot. If one regards such pivots as subjects, then there are constructions in languages which display features of an ergative syntax. I have hypothesized that children initially use a semantic-bootstrapping procedure to construct a syntactically accusative phrase structure. This hypothesis 
predicts that children will have difficulty learning ergative syntactic constructions and will initially fail to recognize the ergative syntactic restrictions. They can eventually acquire such constructions as exceptions to the basic accusative syntactic patterns, but they will not develop a completely ergative syntactic structure.

In section 3.2, I presented data from K'iche' and Kaluli that support this learnability argument. Both languages have syntactically ergative restrictions on focus constructions, and children acquiring these languages initially fail to use the correct ergative syntactic constructions. K'iche' children use the regular active form of the verb to ask questions about subjects, while Kaluli children use the absolutive set of case markers on As in focus position. These errors occur much more frequently than the overgeneralization errors children make with ergative and accusative morphological systems, which suggests that the errors have distinct causes. I claimed that children's errors with morphological systems are performance overgeneralizations. The Kaluli and K'iche' children's errors with the focus constructions appear to be competence overgeneralizations that result from the systematic misanalysis of the ergative constraints on focus constructions.

In denying the existence of syntactically ergative languages I commit myself to the claim that children learn syntactically ergative constructions on a case-by-case basis as exceptions to an accusative phrase structure. In other words, they would proceed as if they were learning the K'iche' focus antipassive. This hypothesis predicts that children learning ergative syntactic constructions would initially treat them accusatively. For example, I would expect children learning Yup'ik Eskimo initially to use verbal postbases with ergative rather than absolutive NPs.

This account also predicts the rarity of languages with syntactically ergative constructions, since such languages represent an extreme departure from an accusative syntax in the sense that they contain the most syntactic rules that operate on an ergative basis. The probability that a language contains a single rule that is an exception to the accusative system is small. The probability that a language contains several rules acting in this manner might be approximately equal to the product of the probabilities of each rule acting in such a fashion. The chance that any language would contain as many syntactically ergative rules as Dyirbal would therefore be slight. This analysis further predicts that languages would show different degrees of syntactic ergativity, from the ergative restrictions on subject accessibility in K'iche' to that and more in Dyirbal.

Most importantly, my hypothesis predicts that syntactically ergative phenomena arise in an idiosyncratic fashion across languages rather than in any consistent pattern. The purposive clause may be peculiar to Dyir- 
bal, while the Yup'ik verbal postbases (Reed et al. 1977, cited in Levin 1983: 127) seem to be peculiarly Eskimo. Syntactically accusative languages like $\mathrm{K}$ 'iche' may nevertheless contain one or two ergative syntactic constructions. The idiosyncratic nature of syntactically ergative constructions would also explain why reflexive verb forms might have an active interpretation in Dyirbal and a passive interpretation in Yup'ik. Compare (13), repeated below, and (31):

(13) Dyirbal (Dixon 1972: 90)

bayi yara buybayiringu

he + ABS man + ABS hides + REFL

'Man hides himself' or 'Man hides (something).'

(31) Yup'ik (Miyaoka (1984: 200)

Neqa-0 iir-tuq

fish + ABS hide +3 sing.

'The fish is hiding' or 'The fish is hidden (by someone).'

The only problem with this hypothesis is that it does not explain why languages would ever adopt ergative syntactic constructions. If it is possible for perfectly accusative languages such as English to function successfully, there would seem to be no reason for languages to go to the extreme of developing ergative pivots for some syntactic rules. Again, there may be factors which favor ergative syntactic constructions (see DuBois 1987); if so, these constructions may have a distribution that is less idiosyncratic than I have suggested.

\section{Conclusion}

I have argued that both morphological and syntactic ergativity create problems that have not been addressed successfully in the current acquisition literature. Ergative languages remain a critical testing ground for theories of syntax and language acquisition because of the way such languages distribute features commonly associated with the 'subject' of a sentence. The defining feature of an ergative language is to put $\mathrm{Os}$ in the same category as Ss at some level of morphosyntactic structure. This feature shows that morphological systems may be independent from syntactic systems to a certain extent. Children cannot rely on morphological data to construct basic syntactic relations or vice versa. The problems of morphological and syntactic ergativity must be resolved independently.

Morphological ergativity poses an acquisition challenge that is fundamentally different from that posed by syntactic ergativity. Children may use distributional-learning procedures to acquire ergative morphological 
systems as easily as they acquire accusative morphological systems. Surface features of the morphological systems, such as the size of the lexical class being inflected, frequent ellipsis, and the number of exceptions, have only a limited impact on children's acquisition of case marking and crossreferencing systems. Children acquiring ergative syntactic constructions, however, produce a much larger proportion of errors relative to the number of obligatory contexts for the construction. These mistakes stem from children's initial adoption of an accusative phrase structure.

I argue that learnability considerations require us to reject Marantz's ergativity hypothesis. This result is an important application of learnability considerations to the evaluation of linguistic theory. Marantz and Levin note that the ergative hypothesis has considerable explanatory advantages in accounting for the otherwise peculiar features of syntactically ergative languages within the government-and-binding framework. I have argued that these theoretical advantages are outweighed by the difficulty of explaining how children would acquire an ergative phrase structure. If syntactically ergative languages are unlearnable, then some other account of ergative syntactic constructions is required.

Dixon's concept of the syntactic pivot provides a better description of the linguistic data and leads to interesting predictions about the acquisition of ergative syntactic structures. His proposal accounts for the rarity of languages with as many ergative features as Dyirbal as well as the idiosyncratic way in which languages manifest syntactic ergativity. However, the notion of a syntactic pivot is really at odds with the basic grammatical notion of subject. The properties of subjects that Marantz and Levin used to support the ergativity hypothesis are fundamental features of noun phrases in a particular structural position - sisters to the verb phrase. If languages are free to redistribute these properties around some syntactic pivot, then the necessity for a structural definition of the syntactic subject disappears. A child's use of one subject property (such as subject-verb agreement) will not necessarily indicate that the child understands or exploits other subject properties (such as restrictions on subject-focus questions or verbal reflexive ambiguities). The exploration of ergative syntactic constructions leads to the question of whether children acquire subjects or pivots. I will have to leave that question for another paper.

Received 22 August 1988

University of Kansas

Revised version received

23 May 1990 


\section{Notes}

1. Earlier versions of this paper were presented at the 1987 Mid-America Linguistics Conference, the Workshop on 'Structure of the Simple Clause' at the Max Planck Institute for Psycholinguistics, the University of Kansas, and the University of British Columbia. I thank those audiences and Melissa Bowerman, Henry Davis, Robert M. W. Dixon, David Ingram, Beth Levin, Michael Maratsos, Richard Weist, and two anonymous reviewers for their comments and suggestions. They are not responsible for any of the remaining defects in style or substance. The research on K'iche' was supported by grants from the Organization of American States, the Wenner-Gren Foundation (Grant No. 3222), and the General Research Fund (Grant No. 3835-X0-0038) of the University of Kansas. The research was made possible in the first place through the kindness and trust of the K'iche' children and families with whom I have worked. I also acknowledge the aid and advice of Augustin Huix Huix and Pedro Quixtan Poz, who have worked closely with me on the transcription and analysis of the K'iche' data. Correspondence address: Department of Linguistics, University of Kansas, Lawrence, Kansas 66045, USA.

2. All K'iche' words are shown in the practical orthography developed by the Proyecto Linguistico Francisco Marroquin (Kaufman 1976) with a single exception: I use <'> rather than $\langle 7\rangle$ for the glottal stop. The other orthographic symbols have their standard IPA values except $\langle\mathrm{tz}\rangle=|\mathrm{ts} /, \quad\langle\mathrm{ch}\rangle=| \mathrm{t} \mathrm{J} /, \quad\left\langle\mathrm{b}^{\prime}\right\rangle=/ 6 /, \quad\left\langle\mathrm{tz} \mathrm{s}^{\prime}\right\rangle=\mid \mathrm{ts} \mathbf{s}^{\prime} /$, $<$ ch' $\rangle=\mid \mathrm{t} \mathrm{f}^{\prime} /,\langle\mathrm{x}\rangle=/ \mathrm{f} /,\langle\mathrm{j}\rangle=\langle\mathrm{X}\rangle$. I use the colon $\langle:\rangle$ to indicate long vowels.

I have also used the following morphological abbreviations: COMP =completive aspect; $\mathrm{INCOMP}=$ incompletive aspect; $\mathrm{PERF}=$ perfect aspect; $1 \mathrm{~A}, 2 \mathrm{~A}, 3 \mathrm{~A}=$ first, second, third person singular absolutive person markers (what Mayanists refer to as 'set B'); IE, 2E, 3E = first, second, third person singular ergative person markers (or 'set A'); PASS = the passive suffix (what Mondloch 1981 refers to as Passive 1), ABS= the absolutive antipassive; $F A=$ the focus antipassive suffix; $R E F L=$ reflexive; $T V=$ the affix-marking-derived transitive verbs; $T T V=$ the clause-final termination marker for root transitive verbs; TIV = the clause-final termination marker for intransitive verbs. Children's language samples in K'iche' include a transcript identification code, for example S2-50. The letter identifies the subject, the number before the hyphen identifies the language sample, and the number following the hyphen identifies the page number. The code S2-50 identifies the 50th page from Al Tiya:n's second language sample.

3. I say at least six because languages often make finer distinctions than the ones I have indicated. I discuss some of these below in section 2.2. Children might also make unsystematic errors in addition to these systematic errors. A child who was simply confused by the morphological system might use the markers at random. Children experiencing momentary difficulties retrieving the proper forms might also produce random errors. I would simply claim that it is possible empirically to distinguish systematic extensions of the sort I outline in this section from the random use of markers which reflects other factors.

4. Table 3 suggests that the children used transitive verbs more frequently than intransitive verbs. This apparent imbalance is due to my excluding the intransitive verbs with thirdperson subjects, since these have a zero morpheme as their agreement marker.

5. I thank Louanna Furbee for bringing this language to my attention. 


\section{Appendix. Person-marker overgeneralizations}

Al Tiya:n

S14 -3

Al Cha:y

R6 -2

$-53$

$-59$

R8 $\quad-57$

R11 -34

R12 - 1

R16 - 14

R18 -23

R23 -20

$-21$ at-pisoj

x-i-'ek

no uj tij b'ik

at, tij e b'inka

at tej

kol at chap taj (k-a-chap)

kal at koj

j-a chupa:m

puta parex

k-0-anoh

no' qa-xutanik

qu-xuranik (at a-piso:m)

'You have wrapped it.'

A Carlos

\begin{tabular}{|c|c|c|c|}
\hline-13 (twice) & a-kula & (ch-at-kula) & 'Come!' \\
\hline-13 (twice) & at a'a-yowik & (x-at-yowik) & 'You gave s.t.' \\
\hline-20 & at e-yowik & (x-at-yowik) & 'You gave s.t.' \\
\hline $12-40$ & u-stinik & (ka-0-sutinik) & 'It's spinning.' \\
\hline $15-43$ & a-koti'ik & (ka-atkote'ik) & \\
\hline $7-24$ & x-0-iloh & (x-r-iloh) & 'He saw it.' \\
\hline-43 & x-ix-loq'wih & (x-i-loq') & 'You all bought it.' \\
\hline $18-29$ & a xa toq'ik & (a x-at-oq'ik) & 'Did you cry?' \\
\hline
\end{tabular}

\section{References}

Aksu-Koc, Ayhan A., and Slobin, Dan I. (1985). The acquisition of Turkish. In The Crosslinguistic Study of Language Acquisition, vol. 1: The Data, D. I. Slobin (ed.). Hillsdale, NJ: Erlbaum.

Anderson, S. (1976). On the notion of subject in ergative languages. In Subject and Topic, C. N. Li (ed.). New York: Academic Press.

Bates, E., and MacWhinney, B. (1982). Functionalist approaches to grammar. In Language Acquisition: The State of the Art. Cambridge: Cambridge University Press.

Bellugi, U. (1968). Linguistic mechanisms underlying child speech. In Proceedings of the Conference on Language and Language Behavior, E. M. Zale (ed.). New York: AppletonCentury-Crofts.

Bowerman, M. (1985). What shapes children's grammars? In The Crosslinguistic Study of Language Acquisition, vol. 2: Theoretical Issues, D. I. Slobin (ed.). Hillsdale, NJ: Erlbaum.

Braine, M. D. S. (1987). What is learned in acquiring word classes - a step toward an acquisition theory. In Mechanisms of Language Acquisition, B. MacWhinney (ed.). Hillsdale, NJ: Erlbaum. 
Brown, R. (1973). A First Language: The Early Stages. Cambridge, MA: Harvard University Press.

Bruner, J. S. (1975). The ontogenesis of speech acts. Journal of Child Language 2, 1-20.

Budwig, N. (1985). I, me, my and 'name': children's early systematizations of forms, meanings and functions in talk about the self. Papers and Reports on Child Language Development 24, 30-37.

Bybee, J. L., and Slobin, D. I. (1982). Rules and schemas in the development and use of the English past. Language 58, 265-289.

Cazden, C. (1968). The acquisition of noun and verb inflections. Child Development 39, 433-448.

Chomsky, N. (1981). Lectures on Government and Binding. Dordrecht: Foris.

Clancy, P. M. (1985). The acquisition of Japanese. In The Crosslinguistic Study of Language Acquisition, vol. 1: The Data, D. I. Slobin (ed.). Hillsdale, NJ: Erlbaum.

Craig, C. G. (1977). The Structure of Jacaltec. Austin: University of Texas Press.

DeLancey, S. (1984). Notes on agentivity and causation. Studies in Language 8 (2), 181-213.

Dixon, R. M. W. (1972). The Dyirbal Language of North Queensland. Cambridge: Cambridge University Press.

-(1979). Ergativity. Language 55, 59-138.

-(1980). The Languages of Australia. Cambridge: Cambridge University Press.

Dowty, D. (1988). Thematic proto-roles, subject selection, and lexical semantic details. Paper presented to annual meeting of the Linguistic Society of America.

DuBois, J. W. (1987). The discourse basis of ergativity. Language 63, 805-855.

Dunn, J. (1987). A preliminary note on Tsimshian oblique subjects. In Papers from the 22nd International Conference on Salish and Neighboring Languages. Victoria, B.C.: University of Victoria.

Fillmore, C. (1968). The case for case. In Universals in Linguistic Theory, E. Bach and R. T. Harms (eds.). New York: Holt, Rinehart and Winston.

Foley, W. A., and Van Valin, R. D., Jr. (1984). Functional Syntax and Universal Grammar. Cambridge: Cambridge University Press.

Gabelentz, H. C. von der (1860). Über das Passivum. Eine sprachvergleichende Abhandlung. Abhandlungen der Königlich Sächsischen Gesellschaft der Wissenschaften, Philologischhistorische Classe 3 (4), 452-546.

Grimshaw, J. (1981). Form, function, and the language acquisition device. In The Logical Problem of Language Acquisition, C. L. Baker and J. J. McCarthy (eds.). Cambridge, MA: MIT Press.

Hale, K. L. (1970). The passive and ergative in language change: the Australian case. In Pacific Linguistic Studies in Honour of Arthur Capell, S. A. Wurm and D. C. Laycock (eds.). Pacific Linguistics C13. Canberra: ANU.

Hoek, D., Ingram, D., and Gibson, D. (1986). An examination of the possible causes of children's early word extensions. Journal of Child Language 13, 477-494.

Huxley, R. (1970). The development of the correct use of subject personal pronouns in two children. In Advances in Psycholinguistics, G. B. Flores D'Arcais and W. J. M. Levelt (eds.). New York: American Elsevier.

Ingram, D. (1989). First Language Acquisition: Method, Description and Explanation. Cambridge: Cambridge University Press.

Karmiloff-Smith, A. (1979). A Functional Approach to Child Language: A Study of Determiners and Reference. Cambridge: Cambridge University Press.

Kaufman, T. (1976). Proyecto de alfabetos y ortografias para escribir las lenguas mayances. Guatemala: Ministerio de Educación.

Keenan, E. L., and Comrie, B. (1977). Noun phrase accessibility and universal grammar. Linguistic Inquiry 8, 63-99. 
Kuczaj, S. (1977). The acquisition of regular and irregular past tense forms. Journal of Verbal Learning and Verbal Behavior 16, 589-600.

Larsen, T. W., and Norman, W. M. (1979). Correlates of ergativity in Mayan grammar. In Ergativity: Towards a Theory of Grammatical Relations, F. Plank (ed.). London: Academic Press.

Levin, B. C. (1983). On the nature of ergativity. Unpublished Ph.D. dissertation, MIT.

MacWhinney, B. (1978). The Acquisition of Morphophonology. Monographs of the Society for Research in Child Development 43, 1-2 (Serial No. 174).

Mallinson, G., and Blake, B. J. (1981). Language Typology: Cross-linguistic Studies in Syntax. Amsterdam: North-Holland.

Marantz, A. P. (1984). On the Nature of Grammatical Relations. Cambridge, MA: MIT Press.

Maratsos, M. P., and Chalkley, M. A. (1980). The internal language of children's syntax: the ontogenesis and representation of syntactic categories. In Children's Language, vol. 2, K. E. Nelson (ed.). New York: Gardner.

-, Gudeman, R., Gerard-Ngo, P., and DeHart, G. (1987). A study in novel word learning: the productivity of the causative. In Mechanisms of Language Acquisition, B. MacWhinney (ed.). Hillsdale, NJ: Erlbaum.

Mills, Anne E. (1985). The acquisition of German. In The Crosslinguistic Study of Language Acquisition, vol. 1: The Data, D. I. Slobin (ed.). Hillsdale, NJ: Erlbaum.

Miyaoka, O. (1984). On the so-called half-transitive verbs in Eskimo. Etudes/Inuit/Studies (Departement d'anthropologie, Université Laval, Québec, Canada), 193-218.

Mondloch, J. L. (1981). Voice in Quiché-Maya. Unpublished dissertation, State University of New York, Albany.

Morokawa, H. (1989). Acquisition of case marking and predicate-argument structures in Japanese. Unpublished Ph.D. dissertation, University of Kansas.

Nichols, J. (1986). Head-marking and dependent-marking grammar. Language 62, 56-119.

Ochs, E. (1982). Ergativity and word order in Samoan child language. Language 58, 646-671.

Perlmutter, D. M. (1989). Multiattachment and the unaccusative hypothesis: the perfect auxiliary in Italian. Probus 1, 63-119.

-, and Postal, P. M. (1977). Toward a universal characterization of passivization. In Proceedings of the Third Annual Meeting of the Berkeley Linguistics Society. Berkeley: University of California.

Pinker, S. (1984). Language Learnability and Language Development. Cambridge, MA: Harvard University Press.

-(1989). Learnability and Cognition: The Acquisition of Argument Structure. Cambridge, MA: MIT Press.

Plank, F. (ed). (1979). Ergativity: Towards a Theory of Grammatical Relations. London: Academic Press.

Postal, P. M. (1977). Antipassive in French. Lingvisticae Investigationes 1 (2), 333-374.

Pye, C. (1985). The acquisition of transitivity in Quiche Mayan. Papers and Reports on Child Language Development 24, 115-122.

-, and Quixtan Poz, P. (1988). Precocious passives (and antipassives) in Quiché Mayan. Papers and Reports on Child Language Development 27, 71-80.

Reed, I., et al. (1977). Yup'ik Eskimo Grammar. Alaska Native Language Center and Yup'ik Language Workshop, University of Alaska, Fairbanks.

Rosen, C. G. (1984). The interface between semantic roles and initial grammatical relations. In Studies in Relational Grammar 2, D. M. Perlmutter and C. G. Rosen (eds.). Chicago: University of Chicago Press. 
Sadock, J. M. (1982). The Bennish optative: a spontaneous ergative construction in child speech. In Chicago Linguistic Society: Papers from the Parasession on Nondeclaratives, 186-193. Chicago: Chicago Linguistic Society.

Schieffelin, B. V. (1985). The acquisition of Kaluli. In The Crosslinguistic Study of Language Acquisition, vol. 1: The Data, D. I. Slobin (ed.). Hillsdale, NJ: Erlbaum.

Silverstein, M. (1976). Hierarchy of features and ergativity. In Grammatical Categories in Australian Languages, R. M. W. Dixon (ed.). Canberra: Australian Institute of Aboriginal Studies.

Slobin, D. I. (1985). Crosslinguistic evidence for the language-making capacity. In The Crosslinguistic Study of Language Acquisition, vol. 2: Theoretical Issues, D. I. Slobin (ed.). Hillsdale, NJ: Erlbaum.

Smoczyńska, M. (1985). The acquisition of Polish. In The Crosslinguistic Study of Language Acquisition, vol. 1: The Data, D. I. Slobin (ëd.). Hillsdale, NJ: Erlbaum.

Sproat, R. (1983). VSO languages and Welsh configurationality. In MIT Working Papers in Linguistics, vol. 5: Papers in Grammatical Theory, I. Haik and D. Massam (eds.). Cambridge, MA: Department of Linguistics and Philosophy, MIT.

Stowell, T. (1981). Origins of phrase structure. Unpublished Ph.D. dissertation, MIT.

Tanz, C. (1974). Cognitive principles underlying children's errors in pronominal casemarking. Journal of Child Language 1, 271-276.

Ullman, M., Pinker, S., Hollander, M., Prince, A., and Rosen, T. J. (1989). Growth of regular and irregular vocabulary and the onset of overgeneralization. Paper presented at the 14th Annual Boston University Conference on Language Development, October.

Van Valin, R. D., Jr. (1981). Grammatical relations in ergative languages. Studies in Language 5 (3), 361-394.

Weist, R. M., and Witkowska-Stadnik, K. (1986). Basic relations in child language and the word order myth. International Journal of Psychology 21, 363-381.

Woodbury, A. C. (1977). Greenlandic Eskimo, ergativity, and relational grammar. In Syntax and Semantics, vol. 8: Grammatical Relations, P. Cole and J. M. Sadock (eds.). New York: Academic Press.

Yokoyama, M., and Schaefer, R. (1986). Suspension of the case particle o in the acquisition of Japanese. Working Papers in Language Development (University of Kansas) 1 (1), 77-104. 